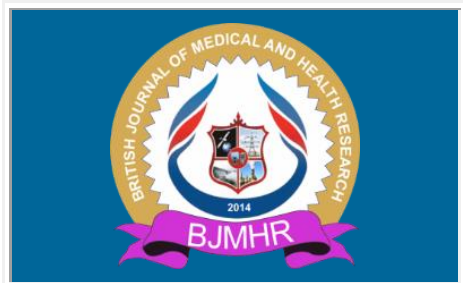

\title{
BJMHR
}

British Journal of Medical and Health Research

Journal home page: www.bjmhr.com

\section{Gender Differences in Electrocardiographic Findings in the Elderly; A Nigerian aging and Health Study.}

Nelson .I. Oguanobi ${ }^{1 *}$, Charles U Odenigbo², Ogonna C Oguejiofor ${ }^{2}$, Ezechukwu Aniekwensi ${ }^{3}$, Uchenna C Okonkwo ${ }^{4}$, Ukamaka M Odenigbo ${ }^{5}$, Tobenna Agogbua ${ }^{1}$

1.Department of Internal Medicine, University of Nigeria Teaching Hospital Enugu,

2.Department of Internal Medicine Nnamdi Azikiwe University Teaching Hospital Nnewi, Anambra State, Nigeria,

3. Department of Medicine, Federal Medical Centre Asaba, Delta State, Nigeria. 4.Department of Medicine, University of Calabar Teaching Hospital, Calabar, Nigeria, 5.Department of Dietetics Federal University of Agriculture Umudike, Abia State, Nigeria

\section{ABSTRACT}

It is postulated that age-related physiologic changes in the elderly would affect the gender variation in electrocardiogram. This study was aimed at comparing electrocardiographic indices and findings in apparently healthy male and female elderly individuals. A total of 66 healthy elderly subjects were recruited for the study. These were drawn from the attendees to the quarterly medical lecture series of the Ebreime Foundation for the Elderly, a Non Governmental Organization. The study was conducted in the medical outpatient clinics of Federal Medical Center, Asaba, Delta State, Nigeria. All subjects had resting 12-lead electrocardiography, background medical history assessment and clinical examination to evaluate their cardiovascular status at rest. The participants were composed of 46 males and 20 females with mean ages \pm (standard deviation) of 69.82(8.1) and 66.05(6.83) respectively. The female participants had significantly higher body mass index and waist and hip circumferences. The overall prevalence of electrocardiographic abnormality was greater in males than females, (89.23\% vs 70.0\%). Significant gender variations were noted in QRS duration and QTc measurements which were all significantly increased in men and women respectively, Among the female participants, significant correlations were noted between QRS duration, PR interval and waist hip ratio and hip circumference respectively, $(\mathrm{r}=-.446 ; \mathrm{P}=.044$ and $\mathrm{r}=-.427 ; \mathrm{P}=.046)$. There were significant gender differences in the occurrence of ST-segment elevation and long QTc $>0.440 \mathrm{~ms}$, which were higher in men and women respectively. High obesity indices correlate with electrocardiographic markers of increased cardiovascular risk in elderly women.

Keywords: Gender, differences, Electrocardiography, elderly

*Corresponding Author Email: nelson.oguanobi@unn.edu.ng

Received 05 January 2021, Accepted 22 February 2021

Please cite this article as: Oguanobi NI et al., Gender Differences in Electrocardiographic Findings in the Elderly; A Nigerian aging and Health Study.. British Journal of Medical and Health Research 2021. 


\section{INTRODUCTION}

Electrocardiography (ECG)is a valuable and relatively inexpensive tool for evaluation of cardiovascular disease. There has been a growing interest in elucidating the gender variations in the electrocardiogram since this fact was first reported in 1920 when Bazell observed that women have longer QT than men ${ }^{1}$.

Subsequent studies have documented gender differences in ventricular repolarization pattern in the electrocardiogram ${ }^{2-4}$. It has been postulated that the physiologic dimorphism between ventricular repolarization in males and females are strongly influenced by changes in the availability or activity of the male sex hormones ${ }^{4}$

Several studies have shown that electrocardiography tests have a lower diagnostic accuracy in women $5,6,7$. The lower accuracy has been attributed to lower ECG voltage, smaller size of the coronary vessels, smaller heart size, hormonal factors (premenopausal relationship with endogenous estrogen levels), breast attenuation, and functional impairment ${ }^{6-8}$.

It is suggested that the sex-related electrocardiographic differences might be age dependent ${ }^{4}$. We postulated that the age-related physiologic changes in the elderly would affect the gender variation in electrocardiogram. This study was designed to compare electrocardiographic indices and findings apparently healthy male and female elderly individuals.

\section{MATERIALS AND METHOD}

A total of 176 elderly participants were screened for the study. These were drawn from the attendees to the quarterly medical lecture series of the Ebreime Foundation for the Elderly, a Non-Governmental Organization. The study was conducted in the medical outpatient clinics of Federal Medical Center, Asaba, Delta State, Nigeria. Ethical approval for the study was granted by the ethical committees of Federal Medical Center, Asaba, Nigeria. Informed consent was obtained from all the participants. All subjects had background medical history assessment with the aid of a questionnaire and then clinically examined to evaluate their cardiovascular status at rest. The weight and height of each subject were recorded and the surface area determined from a standard formula ${ }^{9}$. Only sixty six (66) individual fulfilled the inclusion criteria for apparently healthy subjects. The exclusion criteria for the study were presence of acute illness or history/documentation of chronic illnesses and medications capable of affecting electrocardiogram such as hypertension, diabetes, and significant alcohol intake, use of tobacco, drug abuse and hormonal therapy. Laboratory tests such as serum electrolyte, urea, creatinine, fasting lipid profile (total cholesterol, HDL-cholesterol, LDL, VLDL, triglycerides) and fasting blood glucose were obtained. Resting 12-lead electrocardiography were performed on all subjects using Schiller electrocardiography machine at a paper speed of $25 \mathrm{~mm} / \mathrm{s}$ and standardized at $0.1 \mathrm{mv} / \mathrm{mm}$. A single observer analyzed the electrocardiogram. Measurements 
of the heart rate, cardiac axis, PR- interval, QRS duration and QTc interval were done in the standard fashion ${ }^{10}$. Heart rate correction of the QT-interval was performed using Bazett's formula $(\mathrm{QTc}=\mathrm{QT} / \sqrt{\mathrm{RR}})^{1}$. Standard criteria were followed in the interpretation of morphological electrocardiographic abnormalities ${ }^{10,11}$. We considered the ECG as normal in the presence of regular sinus rhythm within a rate range from 60 to 90 beats/min , normal Pwave, PR interval < $200 \mathrm{~ms}$, normal QRS complex of <110 ms duration, normal ST segment, upright T-waves of $>0.1 \mathrm{mV}$ amplitude in all leads except III, aVR, and V1, and QTc < $440 \mathrm{~ms}^{4,10}$.

\section{Data Analysis}

Data were presented as means \pm standard deviation for continuous variables and as proportions for categorical variables. Comparison of continuous variables between the male and the female were made with independent Student's t-test. For discrete variables distribution between groups were compared with Chi- square test and Fishers exact test as appropriate (where an expected cell is less than 5). All statistical analyses were carried out using the Statistical Packages for Social Sciences (SPSS Inc. Chicago Illinois) software version 11.0 and EPi-Info version 3.4. Statistical tests with probability values less than 0.05 were considered statistically significant.

Intra observer variability of manual ECG measurements was quantified by blinded and randomly sorted repeat measurements of 30 tracings a month after the original measurements were made. There was no statistically significant intra observer variability.

\section{RESULTS AND DISCUSSION}

Electrocardiograms of 66 apparently healthy elderly individuals were analyzed. The participants were mainly retired civil servants, traders, and artisans (Table 1).They were composed of 46 males and 20 females with mean ages \pm (standard deviation) of $69.82(8.1)$ and 66.05(6.83) respectively $\{\mathrm{P}=0.075\}$. The female participants had significantly higher anthropometric indices of body mass index, waist and hip circumferences, (Table 2). The blood pressure indices were comparable in the two groups, (Table 3).

The overall prevalence of electrocardiographic abnormality was greater in males than females. At least one or more electrocardiographic abnormality was noted in $89.23 \%$ of elderly men and $70.0 \%$ of elderly women. Significant gender variations were noted in QRS duration and QTc Measurements which were all significantly increased in men and women respectively, (Table 4).

Among the female participants, significant correlations were noted between QRS duration, PR interval and waist hip ratio and hip circumference respectively, $(\mathrm{r}=-.446 ; \mathrm{P}=.044$ and $\mathrm{r}=-$ $.427 ; \mathrm{P}=.046)$. Analysis of electrocardiographic abnormalities in the participants showed 
Significant gender differences in the occurrence of ST-segment elevation and long QTc > $0.440 \mathrm{~ms}$, which were higher in men and women respectively, (Table 5).

Attempts were made to evaluate the variation of the ventricular transition zone in the precordial leads. This was found to be located in leads $V_{2}$ and $V_{3}$ without any significant sex disparity.

Table 1: Socio-occupational distribution

\begin{tabular}{lllll}
\hline Parameters & \multicolumn{2}{c}{ Frequency $(\%)$} & T-Test & P-Value \\
& Male $(\mathbf{n = 4 6 )}$ & Female (n=20) & & \\
\hline Education & & & & \\
$\begin{array}{l}\text { Primary } \\
\text { Secondary }\end{array}$ & $9(13.04)$ & $3(15.0)$ & & \\
Tertiary & $31(67.39)$ & $12(60.00)$ & & .839 \\
$\begin{array}{l}\text { Occupation } \\
\text { Retiree }\end{array}$ & $33(71.74)$ & $15(75.0)$ & & \\
Trading & $8(17.39)$ & $3(15.0)$ & 7.440 & 0.282 \\
Artisan & $5(10.87)$ & $2(10.0)$ & & \\
Family history & & & & \\
Hypertension & $14(30.43)$ & $5(25.0)$ & 0.201 & .654 \\
Diabetes & $6(13.04)$ & $6(30.0)$ & 0.2694 & .101 \\
Sudden death & $4(8,70)$ & $2(10.0)$ & 0.029 & .865 \\
\hline
\end{tabular}

Table 2: Anthropometric and biochemical parameters

\begin{tabular}{lllll}
\hline Parameters & $\begin{array}{l}\text { Male } \\
\text { Mean (SD) }\end{array}$ & $\begin{array}{c}\text { Female } \\
\text { Mean(SD) }\end{array}$ & T-Test & P-Value \\
\hline Age (years) & $69.82(8.15)$ & $66.05(6.83)$ & 1.811 & 0.075 \\
Weight $(\mathrm{kg})$ & $66.24(10.77)$ & $67.10(13.01)$ & 0.280 & .780 \\
Height $(\mathrm{m})$ & $1.65(0.25)$ & $1.57(0.31)$ & 3.886 & $.001^{*}$ \\
Body mass index $\left(\mathrm{Kg} / \mathrm{m}^{2}\right)$ & $24.42(3.77)$ & $27.55(4.73)$ & 2.854 & $.006^{*}$ \\
Waist circumference & $88.13(9.44)$ & $95.00(10.09)$ & 2.661 & $.010^{*}$ \\
Hip circumference & $94.78(8.99)$ & $103.10(10.25)$ & 3.310 & $.002^{*}$ \\
Waist/Hip ratio & $0.930(0.05)$ & $0.921(0.055)$ & 0.391 & .697 \\
Fasting blood sugar & $4.77(0.89)$ & $4.86(1.40)$ & 0.332 & .741 \\
Creatinine & $99.20(19.52)$ & $100.30(21.19)$ & 0.206 & .838 \\
\hline
\end{tabular}

KEY:

*Statistically significant

Table 3: Blood pressure indices

\begin{tabular}{lllll}
\hline Parameters & $\begin{array}{l}\text { Male } \\
\text { Mean }(\text { SD) }\end{array}$ & $\begin{array}{l}\text { Female } \\
\text { Mean }(\text { SD) }\end{array}$ & T-Test & P-Value \\
& $67.07(13.27)$ & $69.35(9.48)$ & 0.739 & .463 \\
Pulse rate (beat/min) & $125.35(18.35)$ & $124.25(14.98)$ & 0.235 & .815 \\
Erect systolic BP(mmHg) & $77.41(11.56)$ & $82.25(9.24)$ & 1.653 & .103 \\
Erect diastolic BP(mmHg) & $47.93(12.50)$ & $42.00(10.93)$ & 1.838 & .071 \\
Erect pulse pressure $(\mathrm{mmHg})$ & $93.39(12.91)$ & $96.25(10.20)$ & 0.876 & .384 \\
Mean erect arterial BP(mmHg) & $130.98(16.65)$ & $127.25(13.52)$ & .882 & .381 \\
Supine systolic BP(mmHg) & $81.26(11.32)$ & $84.50(7.76)$ & 1.163 & .249 \\
Supine diastolic BP(mmHg) & $49.72(12.12)$ & $42.75(9.52)$ & 2.280 & $.026^{*}$ \\
Supine pulse pressure $(\mathrm{mmHg})$ & $97.83(12.06)$ & $98.75(9.10)$ & 0.305 & .762 \\
Mean Supine systolic BP(mmHg) & & & & \\
\hline KEY:
\end{tabular}

KEY:

*Statistically significant 
Table 4: Gender variation in electrocardiographic parameters

\begin{tabular}{llcll}
\hline Variables & \multicolumn{2}{l}{ Values (Mean SD) } & \multirow{2}{*}{ T- Test } & P- Value \\
\cline { 2 - 3 } & Male & \multicolumn{2}{c}{ Female } & \\
\hline Heart rate (beat/min) & $67.07(15.27)$ & $69.35(9.48)$ & 0.739 & .463 \\
P-wave duration (msec) & $117.22(15.26)$ & $117.90(12.86)$ & .175 & .862 \\
PR- interval (msec) & $176.80(29.91)$ & $172.60(17.51)$ & .585 & .561 \\
QRS duration (msec) & $86.43(10.77)$ & $78.65(8.88)$ & 2.835 & $.0061^{*}$ \\
QT-interval(msec) & $391.41(44.65)$ & $389.20(23.93)$ & .208 & .836 \\
QTc- interval (msec) & $408.65(15.18)$ & $419.40(14.81)$ & 2.680 & $.0099^{*}$ \\
\hline
\end{tabular}

KEY:

*Statistically significant

Table 5: Electrocardiographic findings in the elderly men and women.

\begin{tabular}{llllll}
\hline Findings & \multicolumn{2}{l}{ Frequency $\mathbf{( \% )}$} & & CHI- Square & P-Value \\
& Male & Female & Total & & \\
\hline Left atrial enlargement & $20(43.48)$ & $9(45)$ & $29(43.94)$ & 0.013 & .909 \\
Left axis deviation & $19(41.30)$ & $5(25)$ & $24(36.36)$ & 1.601 & .321 \\
Left ventricular hypertrophy & $7(15.22)$ & $2(10)$ & $9(13.64)$ & 0.322 & .570 \\
ST segment elevation & $14(30.43)$ & $1(5)$ & $15(22.73)$ & 5.135 & $.023^{*}$ \\
T wave inversion & $9(19.57)$ & $7(35)$ & $16(24.24)$ & 1.808 & .179 \\
Bradycardia & $15(32.61)$ & $4(20)$ & $19(28.79)$ & 1.081 & .298 \\
Heart block & $4(8.70)$ & $0(0)$ & $4(6.06)$ & 1.851 & .174 \\
Normal ECG & $5(10.87)$ & $6(30)$ & $11(16.67)$ & 2.475 & .1194 \\
Long QTc & $2(4.35)$ & $5(25.00)$ & $7(10.61)$ & 4.282 & $.0385^{*}$ \\
Right ventricular hypertrophy & $5(10.87)$ & $4(20)$ & $9(13.64)$ & 0.241 & .624 \\
Counter-clockwise rotation & $17(36.96)$ & $7(35)$ & $24(36.36)$ & 0.023 & .879 \\
\hline
\end{tabular}

KEY:

*Statistically significant

Table 6: Ventricular transition zone in the elderly men and women.

\begin{tabular}{lllll}
\hline Precordial Lead & \multicolumn{2}{l}{ Frequency $(\%)$} & CHI- Square & P-Value \\
& Male $(\mathbf{n = 4 6 )}$ & Female $(\mathbf{n = 2 0})$ & & \\
\hline V1 & $2(4.35)$ & $2(10.0)$ & 2.013 & 0.733 \\
V2 & $9(19.57)$ & $7(35.0)$ & & \\
V3 & $16(34.78)$ & $9(45.0)$ & & \\
V4 & $10(21.74)$ & $2(10.0)$ & & \\
V5 & $3(6.52)$ & $0(0)$ & & \\
V6 & $0(0)$ & $0(0)$ & & \\
\hline
\end{tabular}

\section{DISCUSSION}

Recognition and consideration of the gender differences is vital in ensuring the discriminatory value of clinical measurements. This sex-related dimorphism in clinical measurements is often age dependent. A number of studies have reported gender differences in electrocardiographic parameters in young and middle age populations ${ }^{8,12}$. The evaluation of electrocardiographic findings in our study population of elderly individuals revealed higher prevalence of electrocardiographic abnormalities in elderly men (89.23\%) than women(70.0\%). Khane and Surdi reported similar gender variation in a population survey in India although the absolute 
prevalence values were lower than ours $^{8}$. Although a number electrocardiographic abnormalities were observed with greater frequency in the elderly male participants, the differences in most cases were not statistically significant. The only significant observation in the males was the higher occurrence of non-specific ST-segment elevation in 30.43\% compared with $5.0 \%$ in elderly women. The ST-segment abnormalities can reflect inequalities in ventricular recovery, and disparity in recovery of excitability in cardiac muscle ${ }^{8}$. Similar higher occurrence of this early repolarization pattern St-segment elevation was also noted by Zerkiebel et among elderly male subjects in Seychelles $(26.2 \% \text { vs } 2.2 \%)^{12}$. The female participants in our study have reduced QRS duration and increased QTc compared with males. Okin et al reported their findings of decreased PR interval and QRS duration in middle aged female subjects in the United States and attributed these to the smaller cardiac size in females ${ }^{13}$. This explanation is supported by independent observations of significant correlation between QRS duration and left ventricular mass ${ }^{14,15}$. Conversely, greater QRS amplitude and QRS duration in males is as a result of the male hormones and the associated increase in cardiac mass and left ventricular wall thickness. Ironically, many diagnostic criteria on electrocardiography are based on timed wave amplitude values which are inherently sexskewed. This may contribute to the observed lower diagnostic accuracy of electrocardiography in women in previous studies ${ }^{5,6,7}$.

There is a need to develop electrocardiographic diagnostic criteria that take into account the gender variation I depolarization and repolarization pattern. Significant correlations were observed in our study between PR interal, QRS duration, QTc interval and obesity indices in the elderly women. This finding corroborates the observation by De Bacquer et al, of a positive association of these electrocardiographic parameters and obesity ${ }^{16}$. Some other studies have identified QTc as a significant risk predictor for sudden cardiac death in both coronary artery disease and in general population samples with 3 to 5 -fold risk ${ }^{17,18,19}$. It is important to note that the female elderly subjects in our study had significantly higher body mass index, hip circumference, and waist circumference than the male participants. The implication of the increase in measures of obesity in the female population means an increased cardiovascular risk. It has been noted that although the mortality from cardiovascular disease has recently been on the decline in men, it has been increasing in women ${ }^{20}$. This increased mortality in women may be attributed to presence of greater cardiovascular risk factors, inaccurate diagnosis with resultant management inefficiency ${ }^{21}$. In order to curb the trend, accurate identification of high risk individuals for cardiovascular disease for prompt preventive intervention is of prime importance.

\section{CONCLUSION}


Our study has identified some pertinent gender variation in the electrocardiogram of normal aging myocardium. While the elderly men have higher prevalence of non-specific ST-segment elevation, the elderly women have shorter QRS duration and longer QTc interval with significant correlation to the observed increased obesity indices. The challenges of the increased obesity risks and the anatomical peculiarities of women may impart adversely on the accuracy of current electrocardiographic diagnostic criteria.

\section{REFERENCES}

1. Bazett $H$. An analysis of the time-relations of electrocardiograms. Heart $1920 ; 7: 353-370$.

2. Bidoggia H, Maciel JP, Capalozza N, et al. Sex-dependent electrocardiographic pattern of cardiac repolarization. Am Heart J 2000;140:430-436.

3. Lehmann MH, Yang H. Sexual dimorphism in the electrocardiographic dynamics of human ventricular repolarization: characterization in true domain. Circulation 2001;194:32-38.

4. Surawicz B, Parikh SR. Prevalence of Male and Female Patterns of Early Ventricular Repolarization in the Normal ECG of Males and Females From Childhood to Old Age. JACC 2002;40(10):1870-1876

5. Okin PM, Kligfield P. Gender-specific criteria and performance of the exercise electrocardiogram. Circulation. 1995;92:1209-1216.

6. Morise AP, Diamond GA. Comparison of the sensitivity and specificity of exercise electrocardiography in biased and unbiased populations of men and women. Am Heart J. 1995;130:741-747.

7. Hansen CL, Crabbe D, Rubin S. Lower diagnostic accuracy of thallium-201 SPECT myocardial perfusion imaging in women: an effect of smaller chamber size. J Am Coll Cardiol. 1996;28:1214-1219.

8. Rupali S. Khane, Anil D. Surdi. Gender Differences in the Prevalence of Electrocardiogram Abnormalities in the Elderly: A Population Survey in India. Iran J Med Sci. 2012;37(2):92-99

9. Ganong WF. Review of medical physiology. $14^{\text {th }}$ Edition; Appleton and Lange. California; 1989; 236-546.

10. David M Mirvis, Ary L Goldberger. Electrocardiography. In: 26. Zipes D, Libby P, Bonow R, Braunwald E, editors. Braunwald's heart disease, A textbook of cardiovascular medicine. 7th ed. Philadelphia, Pa: WB Saunders Co., 2005:107152. 
11. Hingorani P, Natekar M, Deshmukh S, Karnad DR, Kothari S, Narula D, Lokhandwala Y.

12. Morphological abnormalities in baseline ECGs in healthy normal volunteers participating in phase I studies. Indian J Med Res 2012;135:322-330.

13. Zerkiebel N, Perret F, Bovet P, Abel M, Jaggy C, Paccaud F, Kappenherger L. Electrocardiographic findings in a middle-aged African population in the Seychelles. Journal of electrocardiology 2000; 33(1): 1-15

14. Okin PM, Roman MJ, Dovereux RB et al, Gender differences and the electrocardiogram in left ventricular hypertrophy. Hypertension. 1995;25: 242-249.

15. Gutiu J, Focseneanu L, Rizescu R, et al. Evaluation of the electrocardiographic signs of left ventricular hypertrophy using echocardiography in patients with hypertensive cardiopathy. Rom Journal of Internal Med 1992;30:187-192

16. Okin PM, Roman MJ, Dovereux RB et al, Electrocardiographic identification of increased left ventricular mass by simple voltage-duration products. J. Am. Coll. Cardiol. 1995;25:417-423.

17. De Bacquer D, De Baker G, Kornitzer M. Prevalence of ECG findings in large population based samples of men and women. Heart. 2000;84:625-633.

18. Chugh SS, Reinier K, Singh T, et al., Determinants of prolonged QT interval and their contribution to sudden death risk in coronary artery disease: the Oregon Sudden Unexpected Death Study, Circulation 2009;119: 663-670.

19. Straus SM, Kors JA, De Bruin ML, et al., Prolonged QTc interval and risk of sudden cardiac death in a population of older adults, J. Am. Coll. Cardiol. 2006;47: $362-367$.

20. Algra A, Tijssen JG, Roelandt JR, Pool J, Lubsen J. QTc prolongation measured by standard 12-lead electrocardiography is an independent risk factor for sudden death due to cardiac arrest, Circulation. 1991; 83:1888-1894.

21. Mieres JH, Shaw LJ, Arai A, Budoff MJ, Flamm SD, Hundley WG, et al. Role of noninvasive testing in the clinical evaluation of women with suspected coronary artery disease: Consensus statement from the Cardiac Imaging Committee, Council on Clinical Cardiology, and the Cardiovascular Imaging and Intervention Committee, Council on Cardiovascular Radiology and Intervention, American Heart Association. Circulation 2005; 111: 682-696.

22. Mieres JH, Shaw LJ, Hendel RC, Miller DD, Bonow RO, Berman DS, et al. American Society of Nuclear Cardiology consensus statement: Task Force on Women and Coronary Artery Disease--the role of myocardial perfusion imaging in 
the clinical evaluation of coronary artery disease in women [correction]. J Nucl Cardiol. 2003;10:95-101.

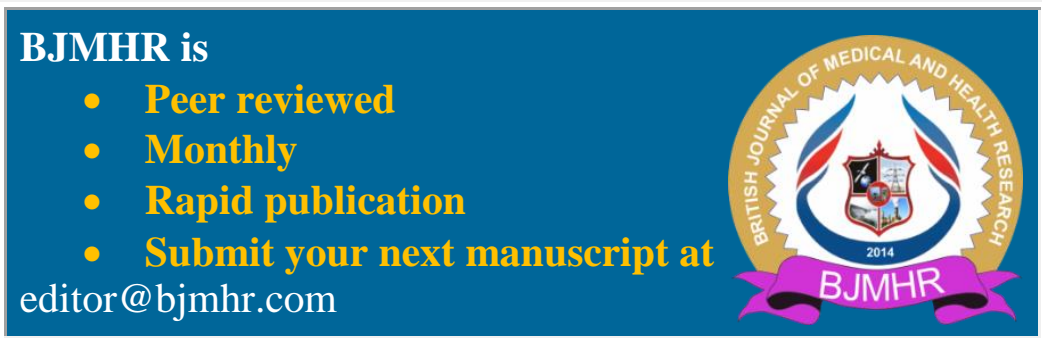

